\title{
ARTí́CULO \\ Potencial de microalgas bentónicas del Mar Caribe como alimento en maricultura
}

Potential of benthic microalgae of the Caribbean Sea as food in mariculture

\author{
Silvia Carrera ${ }^{1 *}$, Luz Adriana Velasco ${ }^{1}$ y Alix Barreto-Hernández ${ }^{1}$ \\ ${ }^{1}$ Laboratorio de Moluscos y Microalgas, Universidad del Magdalena, Carrera 32 № 22-08, Santa Marta, Colombia. \\ *silviacrisco@yahoo.com
}

\begin{abstract}
For the development of marine aquaculture in the Caribbean, the availability of local benthic microalgae as food is desirable. In this work, 6 strains of benthic microalgae were isolated and their potential for use in aquaculture was evaluated by analyzing their size, cell density, growth rate, proximal composition, as well as their capacity to produce biomass on plates under culture conditions indoor and outdoor. Three diatoms (Cylindrotheca closterium, Entomoneis alata, and Plagiotropis lepidoptera), two cyanobacteria (Komvophoron crassum and Synechococcus sp.) and one chlorophyte (Tetraselmis chuii) were isolated and described. The cyanobacteria had the smallest cell sizes, while the diatoms had the largest. Under planktonic culture conditions, the highest algal density was presented by Synechococcus sp. while the highest growth rate occurred in E. alata. Higher protein content and protein/energy ratio were present in diatoms, carbohydrates in Tetraselmis chuii and cyanobacteria, while those of lipids and energy were recorded in the diatoms E. alata and P. lepidoptera. Under benthic culture conditions, the highest biomass production and growth rate was obtained in cyanobacteria and $P$. lepidoptera. Most of the microalgae exhibited higher values of biomass settled in indoor than outdoor conditions, as well as similar growth rates in both sites. In conclusion, given the size, proximal composition, settled biomass and growth rate, all isolated benthic microalgae have the same potential to be used as food in marine aquaculture.
\end{abstract}

Key words: Growth, density, biomass, diatoms, chlorophytes, cyanobacteria

Resumen.- Para el desarrollo de la acuicultura marina en el Caribe es deseable la disponibilidad de microalgas bentónicas locales como alimento. En este trabajo, se aislaron seis cepas de microalgas bentónicas y se evaluó su potencial para utilizarlas en acuicultura mediante el análisis de su tamaño, densidad celular, tasa de crecimiento, composición proximal, así como su capacidad para producir biomasa sobre placas bajo condiciones de cultivo bajo techo y en exterior. Se aislaron y describieron tres diatomeas (Cylindrotheca closterium, Entomoneis alata y Plagiotropis lepidoptera), dos cianobacterias (Komvophoron crassum y Synechococcus sp.) y una clorófita (Tetraselmis chuii). Las cianobacterias presentaron los menores tamaños celulares, mientras que las diatomeas los mayores. Bajo condiciones de cultivo planctónico, la mayor densidad algal la presentó Synechococcus sp., mientras que la mayor tasa de crecimiento ocurrió en E. alata. Mayores contenidos de proteínas y relación proteínas/energía se presentaron en las diatomeas, los de carbohidratos en Tetraselmis chuii y las cianobacterias, mientras que los de lípidos y energía se registraron en las diatomeas $E$. alata y $P$. lepidoptera. Bajo condiciones de cultivo bentónico, la mayor producción de biomasa y tasa crecimiento se obtuvo en las cianobacterias y en $P$. lepidoptera. La mayoría de las microalgas exhibieron mayores valores de biomasa asentada en condiciones bajo techo y en exterior, así como similares tasas de crecimiento en los dos sitios. En conclusión, dado el tamaño, composición proximal, biomasa asentada y tasa crecimiento, todas las microalgas bentónicas aisladas tienen el mismo potencial para ser usadas como alimento en acuicultura marina.

Palabras clave: Crecimiento, densidad, biomasa, diatomeas, clorófitas, cianobacterias

\section{INTRODUCCIÓN}

En los últimos años, se han llevado a cabo varios esfuerzos en desarrollar la acuicultura marina en el Caribe como alternativa de producción pesquera (Lovatelli \& Sarkis 2011, Alvarez-Lajonchère \& Ibarra-Castro 2013). Muchos de los animales marinos considerados de interés acuícola atraviesan por fases de su desarrollo en que son ramoneadores o alimentadores de depósito, que bajo condiciones de laboratorio requieren de microalgas bentónicas como alimento (Reitan et al. 1997, Zupo et al. 2018).
A nivel mundial se han realizado varios esfuerzos para aislar microalgas marinas bentónicas con fines de acuicultura. Esto ha permitido que la industria cuente con cepas propias de zonas subtropicales y templadas de los océanos Índico y Pacífico (Kawamura et al. 1998, Renaud et al. 1999, Correa-Reyes et al. 2001, Knuckey et al. 2002, Chen 2007, Xing et al. 2007, Kwon et al. 2013, Yang et al. 2014, Jiménez-Valera \& Sánchez-Saavedra 2016). Sin embargo, en el Caribe estos esfuerzos han sido escasos (Almaguer et al. 2004, Leal et al. 2013, Barreto-Hernández \& Velasco 2014), dificultando la obtención de microalgas bentónicas nativas, adaptadas a las condiciones locales y 
que brinden una adecuada calidad nutricional, sin el riesgo de realizar introducciones indeseadas en los ecosistemas locales.

El cultivo de las microalgas bentónicas puede realizarse usando técnicas estándar para algas planctónicas (Simental \& Sánchez-Saavedra 2003, Curbelo et al. 2004, RodríguezNúñez et al. 2015), útiles para producir inóculos en los cultivos bentónicos o para alimentar organismos planctotróficos. No obstante, para ser usadas como alimento vivo de organismos alimentadores de depósito, deben ser cultivadas en sistemas bentónicos, ya sea en condiciones bajo techo (Kawamura et al. 1998, De la Peña 2007, Xing et al. 2007, Keun-Ko \& Bum-Hur 2011) o bien exterior (Watson et al. 2004, De la Peña 2007).

Entre las características que deben tener las microalgas bentónicas para ser útiles como alimento vivo en acuicultura son: 1) tamaño celular apropiado, que permita su ingestión (entre 2 y $60 \mu \mathrm{m}$, Brown et al. 1997, Cognie et al. 2001); 2) alta digestibilidad (Kawamura et al. 1995, Onitsuka et al. 2007); 3) alta capacidad para crecer (Barsanti \& Gualtieri 2005); 4) alta capacidad para colonizar sustratos de forma homogénea y densa, así como competir eficientemente con otras especies (Searcy-Bernal et al. 2001, Najmudeen 2017); 5) tolerancia a condiciones de cultivo bajo techo como exterior (De la Peña 2007); y 6) altos valores de contenido de proteína (Utting 1986) y relación proteína/ energía (Saucedo et al. 2013).

El presente estudio se realizó con el propósito de contribuir al establecimiento de un cepario de microalgas bentónicas nativas del Caribe, y determinar el potencial de las mismas para su uso como alimento en acuicultura.

\section{Materiales Y MÉTOdoS}

Se aislaron 6 microalgas bentónicas y se analizó su tamaño, densidad, tasa de crecimiento y su composición proximal bajo condiciones de cultivo planctónico, así como su producción de biomasa sobre sustratos bajo condiciones de cultivo bajo techo y en exterior.

\section{Aislamiento E IDENTIFICACIÓn de LAS MiCroalgaS}

Las microalgas fueron aisladas de muestras de perifiton (1-5 $\mathrm{mg}$ ) tomadas en el intermareal rocoso a partir del raspado de rocas o de placas de PVC ancladas a $1 \mathrm{~m}$ de profundidad en Taganga ( $11^{\circ} 16^{\prime} 4,27^{\prime}$ 'N; 74¹1'45,67'W) y El Rodadero (11 $\left.{ }^{\circ} 12,5^{\prime} 43,5^{\prime \prime} \mathrm{N} ; 74^{\circ} 14^{\prime} 34,7^{\prime \prime} \mathrm{W}\right)$, Santa Marta, Colombia, entre marzo 2012 y enero 2013. En esta zona, la temperatura oscila entre 23 y $32^{\circ} \mathrm{C}$, la salinidad varía entre 31 y 36 , y el pH entre 7,25 y 8,5 (Vivas-Aguas et al. 2015).

Las muestras fueron inoculadas en tubos de ensayo con $10 \mathrm{~mL}$ de medio de cultivo de Guillard F/2 (Guillard \& Ryther 1962) preparado con agua de mar a $30 \pm 1$ de salinidad. Luego se transportaron al Laboratorio de
Moluscos y Microalgas de la Universidad del Magdalena, Colombia $\left(11^{\circ} 16^{\prime} 58^{\prime \prime} \mathrm{N}\right.$; $\left.74^{\circ} 10^{\prime} 48^{\prime \prime} \mathrm{W}\right)$ donde se incubaron en condiciones constantes de intensidad lumínica (1.500 \pm 2 Lux $)$, temperatura $\left(22 \pm 0,5{ }^{\circ} \mathrm{C}\right)$ y agitación manual dos veces al día. Diariamente se tomaron muestras $(1 \mathrm{~mL})$ de cada tubo de ensayo con cultivo primario las cuales se examinaron bajo un microscopio de luz NIKON ${ }^{\circledR}$ Eclipse E100, en aumentos de 40x y 100x para detectar la presencia de microalgas y aplicar la técnica de diluciones seriadas de 1:10 a aquellas muestras positivas (Guillard 1973). Los cultivos diluidos positivos fueron usados para aplicar la técnica de rayado en placa (Hoshaw \& Rosowski 1973). Para ello, con un asa metálica se tomaron muestras de cada cultivo y se sembraron individualmente en cajas Petri con medio de cultivo Guillard F/2 (15 mL) y agar $\left(20 \mathrm{~g} \mathrm{~L}^{-1}\right.$ de medio). El procedimiento fue repetido varias veces usando como inóculo muestras de las diferentes colonias que se desarrollaban en este medio hasta verificar el aislamiento de una sola especie, de acuerdo a la tipificación de la colonia y su verificación bajo el microscopio.

Las microalgas que se lograron aislar fueron mantenidas en medio Guillard F/2 sólido en placas de Petri y líquido en tubos de ensayo bajo las mismas condiciones descritas, en la Colección de Microalgas Marinas de la Universidad del Magdalena, Colombia (UMC-MA, Registro Nacional de Colecciones Biológicas $\mathrm{N}^{\circ}$ 205). A los cultivos en medio sólido se les hizo una renovación mensual del medio, mientras que a los mantenidos en medio líquido esta operación se realizó cada 15 días. La identificación de las microalgas aisladas a nivel de especie así como su caracterización se realizó bajo el microscopio de luz a aumentos de 100x en la mayoría de las cepas. Para Synechococcus sp. y Tetraselmis chuii fue necesario usar microscopía electrónica de barrido (SEM) luego de que las células fueron centrifugadas, enjuagadas con una solución tamponada de fosfato sódico $(\mathrm{pH}=7,3)$, fijadas con una solución de glutamato aldehído (2,5\%), lavadas con agua destilada, deshidratadas en etanol (30, 50, 70 y 100\%) y recubiertas con oro de paladio. Las especies de microalgas fueron identificadas siguiendo los textos de Hoek et al. (1995) y Vidal (2010). La longitud o medida de mayor tamaño de las células de cada microalga se estimó a partir de la medición de 20 células tomadas al azar usando la reglilla del microscopio de luz. El área se determinó mediante el programa Scion Image 4 (Scion Corporation). La forma de crecimiento de cada microalga se estableció siguiendo los criterios de Kawamura \& Hirano (1992).

\section{Cultivo en Sistema Planctónico}

Cada una de las cepas aisladas se cultivó en 4 recipientes cerrados de vidrio de $500 \mathrm{~mL}$ esterilizados y provistos con el medio Guillard F/2 (250 mL). Cada cultivo réplica fue mantenido en condiciones de iluminación artificial constante de 1.500 Lux, temperatura de $25 \pm 1{ }^{\circ} \mathrm{C}$, salinidad de $30 \pm$ 
$1, \mathrm{pH}$ de 7,75 $\pm 1,42$ y una densidad inicial de 5,6 $\pm 0,6 \mathrm{x}$ $10^{5}$ cél $\mathrm{mL}^{-1}$. Los inóculos de cada tratamiento provinieron de un mismo cultivo, y estos cultivos fueron previamente aclimatados por lo menos durante 3 generaciones a las condiciones experimentales de cada tratamiento. Diariamente, se repuso la pérdida de agua por evaporación de cada réplica, añadiendo agua destilada hasta completar el nivel inicial.

Diariamente, se tomaron 3 muestras $(1 \mathrm{~mL})$ en 3 réplicas de cultivo de cada microalga, luego de despegar las células adheridas a las paredes del recipiente y homogenizar la solución por agitación. Estas muestras se colocaron en un hematocitómetro Neubauer y se cuantificó la densidad celular bajo un microscopio de luz. La tasa de crecimiento o duplicación de células por día $(\mu)$ para cada réplica se estimó de acuerdo con la ecuación descrita por Wood et al (2005):

$$
\mu=\left(\operatorname{Ln~} \mathrm{N}_{1}-\operatorname{Ln} \mathrm{N}_{0}\right) /\left(\mathrm{t}_{1}-\mathrm{t}_{0}\right)
$$

Donde $\mathrm{N}_{1}=$ densidad celular al tiempo $1\left(\mathrm{t}_{1}\right)$ and $\mathrm{N}_{0}=$ densidad celular al tiempo $0\left(\mathrm{t}_{0}\right)$.

A una de las réplicas de cada tratamiento se le monitoreó diariamente la temperatura $\left({ }^{\circ} \mathrm{C}\right)$, el $\mathrm{pH}$ mediante un equipo medidor YSI (precisión $0,1^{\circ} \mathrm{C}$ y 0,1 , respectivamente) y la salinidad con un refractómetro portátil (precisión 1 ppt). La intensidad lumínica se midió con un luxómetro Lutron ${ }^{\circledR}$ L-X-101 (precisión 1 Lux).

\section{ANÁLISIS PROXIMALES}

Para establecer el contenido proximal de cada una de las cepas aisladas, estas se cultivaron en el sistema planctónico descrito en el apartado anterior, pero usando recipientes plásticos de mayor tamaño (2 L) y provistos de aireación. En el cuarto día de cultivo, se colectó una muestra ( $13 \mathrm{~g}$ de biomasa húmeda) de cada cultivo réplica. Estas muestras fueron obtenidas mediante centrifugación en frío (4.000 rpm por $11 \mathrm{~min}$ y a $12{ }^{\circ} \mathrm{C}$ ) y posteriormente se lavaron con formiato isotónico para eliminar los cristales de sal.

La determinación de la humedad, contenido orgánico y cenizas se realizó de acuerdo a los procedimientos establecidos en el método 930,04 (AOAC 2000). La cuantificación de lípidos se realizó por el método de Folch modificado por Bligh \& Dyer (1959), mientras que la de proteínas se realizó siguiendo el método de Kjeldahl (AOAC 2000) y el de carbohidratos se calculó de la diferencia del contenido orgánico y el de proteínas y lípidos (AOAC 2000). El contenido de energía de cada microalga se estimó de la sumatoria del producto del contenido de estas macromoléculas orgánicas por sus equivalentes energéticos $1 \mathrm{mg}$ de proteína $=20,1 \mathrm{~J}, 1 \mathrm{mg}$ de carbohidratos=17,2 J y $1 \mathrm{mg}$ de lípidos= 35,3 J (Brokordt \& Guderley 2004). La relación proteína / energía se estimó de dividir el peso seco de proteína sobre la cantidad de energía en Joules (J) presentes en un mg de dieta.

\section{EXPERIMENTO DE CULTIVO BENTÓNICO}

Se evaluó la producción de biomasa adherida sobre sustratos duros para cada una de las microalgas aisladas en dos lugares de cultivo: 1) bajo techo, a una temperatura de $25,1 \pm 1,0{ }^{\circ} \mathrm{C}$ e iluminación artificial constante de $888 \pm 20$ Lux y 2) en exterior, a una temperatura de $28,1 \pm 2,0^{\circ} \mathrm{C}$, e iluminación artificial en la noche y natural durante el día de $1655 \pm$ 305 Lux. Cada uno de los tratamientos se llevó a cabo por cuadruplicado, usando acuarios plásticos de 12 L cubiertos con películas plásticas transparentes. En cada acuario se suspendieron verticalmente 12 placas de PVC transparentes y plegadas $(25 \times 15 \mathrm{~cm})$ y se agregaron $10 \mathrm{~L}$ de medio $\mathrm{F} / 2$ elaborado con agua de mar microfiltrada a $1 \mu \mathrm{m}$ e inóculos de microalgas para generar una densidad inicial de 9,4 $\pm 1,6$ x $10^{5}$ cél $\mathrm{mL}^{-1}$. El manejo de los inóculos y de la evaporación del agua fue el mismo descrito en los cultivos planctónicos. Todas las réplicas fueron mantenidas a valores constantes de salinidad $(35 \pm 1)$ y $\mathrm{pH}(8,02 \pm 0,07)$.

Cada 48 h se determinó la biomasa seca de las microalgas asentadas sobre los sustratos a partir de una placa tomada al azar de cada acuario réplica. Todo el material fijado en cada placa fue desprendido y colectado individualmente con ayuda de un pincel y agua de mar microfiltrada (1 $\mu \mathrm{m})$. Este material fue filtrado con ayuda de una bomba de vacío sobre filtros de fibra de vidrio previamente lavados y pesados (diámetro de poro de $0,45 \mu \mathrm{m}$ ). Los filtros con muestras fueron secados $\left(70{ }^{\circ} \mathrm{C}\right.$ x $48 \mathrm{~h}$ ) y posteriormente pesados (Strickland \& Parsons 1972). La biomasa seca se cuantificó a partir de la diferencia entre el peso final de los filtros con muestras y el peso inicial de los filtros. La tasa de crecimiento $(\mu)$ para cada réplica se estimó mediante la misma ecuación empleada en los cultivos planctónicos, pero teniendo en cuenta la biomasa de las microalgas en lugar de la densidad celular. Tres veces al día se registró el $\mathrm{pH}$, temperatura, salinidad e intensidad lumínica en cada réplica.

\section{ANÁLISIS ESTADíSTICOS}

Con el fin de establecer la existencia de diferencias significativas en la producción celular y de biomasa entre las cepas microalgales y/o condiciones de cultivo, se llevaron a cabo análisis de varianza de medidas repetidas a una o dos vías, verificando el cumplimiento del supuesto de esfericidad. Para establecer la existencia de diferencias significativas en los valores de $\mu$ y la composición proximal de las diferentes microalgas, se llevaron a cabo análisis de varianza a una vía. Finalmente, se realizaron análisis de correlación de Spearman con el propósito de establecer la existencia de alguna correlación entre la constante de crecimiento relativo de las diferentes cepas, su tamaño, peso, área, relación área/peso y composición proximal. Para todos los casos se verificó el cumplimiento de los supuestos de homogeneidad de varianza y normalidad. Los análisis estadísticos se efectuaron mediante el programa estadístico IBM ${ }^{\circledR}$ SPSS $®$ Statistics 20. Para las decisiones se usó un nivel de significancia del $95 \%$. 


\section{RESUltados}

\section{CARACTERIZACIÓN MORFOLÓGICA}

De las 6 microalgas bentónicas aisladas, tres fueron diatomeas pennadas, dos cianobacterias y una clorófita. La diatomea Cylindrotheca closterium mostró movimientos rápidos, no formó colonias en medio líquido, presentó débil adhesión al sustrato y el mayor tamaño de todas las especies aisladas (Fig. 1A, Tabla 1). Las diatomeas Entomoneis alata y Plagiotropis lepidoptera tampoco formaron colonias en medio líquido, presentaron movimientos lentos, fuerte adhesión al sustrato y tamaños relativamente grandes (Figs. 1B-C, Tabla 1). En cuanto a las cianobacterias Komvophoron crassum y Synechococcus sp., éstas no mostraron movimiento y sus células presentaron los menores tamaños entre todas las microalgas aisladas (Fig. 1D-E, Tabla 1).
Mientras $K$. crassum presentó un tipo de crecimiento eréctil y colonial en medio líquido, Synechococcus sp. creció de forma postrada, adhiriéndose fuertemente al sustrato y no formó colonias en medio líquido. Finalmente, la clorófita flagelada Tetraselmis chuii exhibió movimiento en las células mantenidas en el plancton cuando los cultivos se mantuvieron con agitación, en ausencia de ésta, presentó fuerte adhesión al sustrato, y un tamaño intermedio con relación a las demás microalgas aisladas (Fig. 1F, Tabla 1).

\section{EXPERIMENTO DE CULTIVO EN SISTEMA PLANCTÓNICO}

Los cultivos planctónicos de las microalgas aisladas iniciaron con una densidad promedio de $5,6 \times 10^{5}$ cél $\mathrm{mL}^{-1}$ y alcanzaron valores máximos de 46 y $97,5 \times 10^{5}$ cél $\mathrm{mL}^{-1}$ (Fig. 2) entre los 4 y 10 días de cultivo. Los mayores valores de densidad algal se obtuvieron con las microalgas

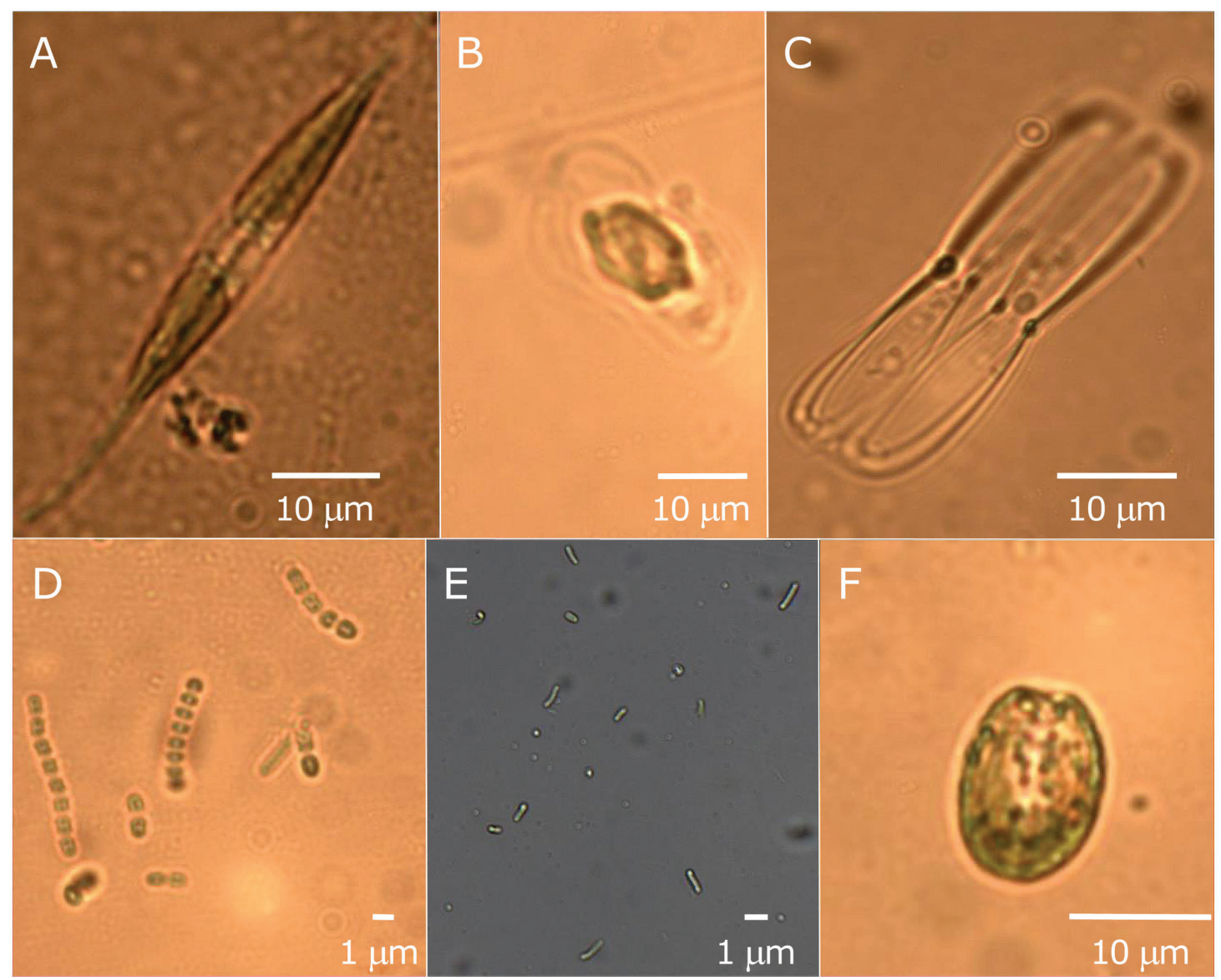

Figura 1. Microalgas bentónicas aisladas en Santa Marta, Colombia. A) Cylindrotheca closterium, B) Entomoneis alata, C) Plagiotropis lepidoptera, D) Komvophoron crassum, E) Synechococcus sp. y F) Tetraselmis chuii. Fotos tomadas por los autores con microscopio óptico (100x) / Benthic microalgae isolated in Santa Marta, Colombia. A) Cylindrotheca closterium, B) Entomoneis alata, C) Plagiotropis lepidoptera, D) Komvophoron crassum, E) Synechococcus sp. and F) Tetraselmis chuii. Photos taken by the authors with an optical microscope (100 x) 
Tabla 1. Caracterización de 6 cepas de microalgas bentónicas aisladas en el litoral rocoso de Santa Marta, Caribe Colombiano. Valores promedio y errores estándar de la longitud, área, peso, relación área/peso, y forma de crecimiento de acuerdo a Kawamura \& Hirano (1995) / Characterization of 6 strains of benthic microalgae isolated in the rocky coast of Santa Marta, Colombian Caribbean. Average values and standard errors of length, area, weight, area/weight ratio, relative growth constant (K), maximum density and shape of growth according to Kawamura \& Hirano (1995)

\begin{tabular}{|c|c|c|c|c|c|}
\hline Microalga & $\begin{array}{l}\text { Longitud } \\
\qquad(\mu \mathrm{m})\end{array}$ & $\begin{array}{l}\text { Área } \\
\left(\mu \mathrm{m}^{2}\right)\end{array}$ & $\begin{array}{c}\text { Peso } \\
\left(\mu \mathrm{g} \text { cél }^{-1}\right)\end{array}$ & $\begin{array}{l}\text { Relación área/peso } \\
\qquad\left(\mu \mathrm{m}^{2} \mu \mathrm{g}^{-1}\right)\end{array}$ & $\begin{array}{l}\text { Forma de } \\
\text { crecimiento }\end{array}$ \\
\hline \multicolumn{6}{|l|}{ Bacillariophyta } \\
\hline Cylindrotheca closterium & $61,07 \pm 1,4^{\mathrm{a}}$ & $94,5 \pm 6^{b}$ & $139 \pm 1^{\mathrm{b}}$ & $0,67 \pm 0,01^{\mathrm{b}}$ & A \\
\hline Entomoneis alata & $38,32 \pm 0,7^{\mathrm{c}}$ & $76 \pm 2^{c}$ & $178 \pm 5^{\mathrm{a}}$ & $0,42 \pm 0,19^{\mathrm{c}}$ & B \\
\hline Plagiotropis lepidoptera & $44,41 \pm 3,7^{\mathrm{b}}$ & $239 \pm 31^{\mathrm{a}}$ & $89 \pm 7^{\mathrm{c}}$ & $2,66 \pm 0,12^{\mathrm{a}}$ & B \\
\hline \multicolumn{6}{|l|}{ Cyanophyta } \\
\hline Komvophoron crassum & $1,35 \pm 0,3^{\mathrm{d}}$ & $3,2 \pm 0,1^{\mathrm{e}}$ & $97 \pm 2^{\mathrm{c}}$ & $0,03 \pm 0,24^{\mathrm{d}}$ & $\mathrm{C}$ \\
\hline Synechococcus sp. & $2,39 \pm 0,2^{\mathrm{d}}$ & $5,5 \pm 0,2^{\mathrm{e}}$ & $64 \pm 9^{d}$ & $0,08 \pm 0,01^{\mathrm{d}}$ & B \\
\hline \multicolumn{6}{|l|}{ Clorophyta } \\
\hline Tetraselmis chuii & $10,60 \pm 0,9^{\mathrm{c}}$ & $39 \pm 2,2^{d}$ & $72 \pm 5^{\mathrm{d}}$ & $0,53 \pm 0,03^{\mathrm{bc}}$ & B \\
\hline
\end{tabular}

Las letras diferentes indican diferencias significativas entre microalgas $(P<0,05)$

$\mathrm{A}=$ Formas postradas de débil adhesión $\mathrm{y}$ con movimientos rápidos, $\mathrm{B}=$ formas postradas fuertemente adhesivas y con movimientos lentos, $\mathrm{C}=$ formas no móviles de crecimiento eréctil
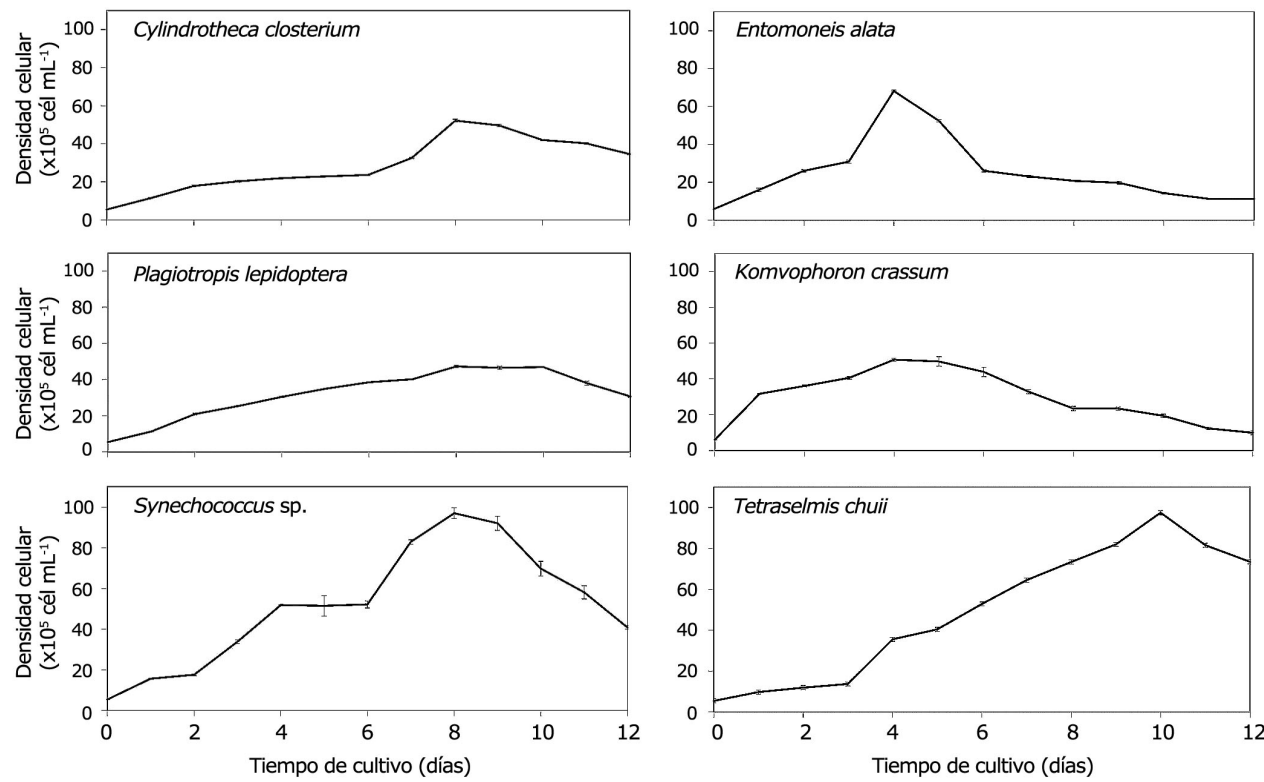

Figura 2. Densidad celular (cél $\mathrm{mL}^{-1}$ ) de 6 especies de microalgas bentónicas del Caribe mantenidas en condiciones de cultivo planctónico bajo techo. Las barras verticales corresponden al error estándar / Cell density (cell mL ${ }^{-1}$ ) of 6 species of benthic microalgae from the Caribbean maintained under indoor planktonic culture conditions. The vertical bars correspond to the standard error

Synechococcus sp. seguido por T. chuii, y luego E. alata, mientras que los menores se evidenciaron en P. lepidoptera, C. closterium y K. crassum $(\mathrm{gl}=5, \mathrm{~F}=476,028, P<0,001)$. Los valores de tasa de crecimiento $\mu$ oscilaron entre 0,39 y 0,79 div día ${ }^{-1}$ (Tabla 2), siendo mayores los obtenidos en $E$. alata, siguiéndole $K$. crassum, mientras que los menores se presentaron en $T$. chuii, C. closterium y P. lepidoptera $(\mathrm{gl}=$ $5, \mathrm{~F}=811,240, P<0,001$, Fig. 3 ).
No se encontró ninguna correlación significativa entre los valores de densidad máxima o $\mu$ de las microalgas en cultivo planctónico con su tamaño $(\mathrm{n}=6, \mathrm{r}=-0,600, P>0,208)$, peso $(\mathrm{n}=6, \mathrm{r}=0,086, P>0,05)$, área $(\mathrm{n}=6, \mathrm{r}=-0.116, P>0.05)$ y relación área/peso $(\mathrm{n}=6, \mathrm{r}=-0,143, P>0,05)$. 
Tabla 2. Composición proximal y parámetros de crecimiento de 6 microalgas bentónicas aisladas en el Caribe y cultivadas en sistema planctónico. Los valores corresponden a los promedios \pm errores estándar / Proximal composition and growth parameters of 6 benthic microalgae isolated in the Caribbean and cultured in batch planktonic. The values correspond to the averages \pm standard errors

\begin{tabular}{|c|c|c|c|c|c|c|c|}
\hline Microalgas & $\begin{array}{c}\text { Densidad } \\
\text { máxima } \\
\left(\text { x } 10^{5} \text { cél } \mathrm{mL}^{-1}\right)\end{array}$ & $\begin{array}{c}\mu \\
\mu\left(\operatorname{div}^{-1} \operatorname{dí}^{-1}\right)\end{array}$ & $\begin{array}{l}\text { Proteínas } \\
\qquad(\%)\end{array}$ & $\begin{array}{c}\text { Carbohidratos } \\
(\%)\end{array}$ & $\begin{array}{l}\text { Lípidos } \\
(\%)\end{array}$ & $\begin{array}{l}\text { Energía } \\
\left(\mathrm{J} \mathrm{mg}^{-1}\right)\end{array}$ & $\begin{array}{l}\text { Relación } \\
\text { proteína/energía } \\
\left(\mathrm{mg} \mathrm{J}^{-1}\right)\end{array}$ \\
\hline \multicolumn{8}{|l|}{ Bacillariophyta } \\
\hline Cylindrotheca closterium & $52,2 \pm 7,2^{d}$ & $0,40 \pm 0,00^{\mathrm{d}}$ & $36,5 \pm 0,4^{\mathrm{a}}$ & $35,8 \pm 1,6^{\mathrm{c}}$ & $15,5 \pm 0,8^{\mathrm{e}}$ & $18,49 \pm 0,1^{\mathrm{d}}$ & $1,94 \pm 0,013^{\mathrm{a}}$ \\
\hline Entomoneis alata & $68,2 \pm 4,7^{\mathrm{c}}$ & $0,79 \pm 0,00^{\mathrm{a}}$ & $27,6 \pm 0,2^{b}$ & $2,2 \pm 0,5^{\mathrm{d}}$ & $50,2 \pm 0,1^{\mathrm{a}}$ & $23,48 \pm 0,1^{\mathrm{a}}$ & $1,16 \pm 0,011^{\mathrm{b}}$ \\
\hline Plagiotropis lepidoptera & $47,2 \pm 1,8^{\mathrm{d}}$ & $0,39 \pm 0,00^{\mathrm{d}}$ & $26,6 \pm 0,6^{b}$ & $4,6 \pm 0,6^{\mathrm{d}}$ & $45,6 \pm 0,2^{b}$ & $22,04 \pm 0,1^{b}$ & $1,19 \pm 0,023^{\mathrm{b}}$ \\
\hline \multicolumn{8}{|l|}{ Cyanophyta } \\
\hline Komvophoron crassum & $50,7 \pm 3,1^{\mathrm{d}}$ & $0,75 \pm 0,01^{\mathrm{b}}$ & $8,6 \pm 0,2^{\mathrm{d}}$ & $54,7 \pm 1,2^{b}$ & $23,7 \pm 0,4^{\mathrm{d}}$ & $19,14 \pm 0,1^{\mathrm{d}}$ & $0,43 \pm 0,014^{\mathrm{d}}$ \\
\hline Synechococcus sp. & $97,4 \pm 26,6^{\mathrm{a}}$ & $0,55 \pm 0,00^{\mathrm{c}}$ & $12,8 \pm 1,0^{\mathrm{c}}$ & $56,2 \pm 0,8^{b}$ & $27,1 \pm 0,1^{\mathrm{c}}$ & $21,19 \pm 0,3^{\mathrm{c}}$ & $0,51 \pm 0,063^{\mathrm{d}}$ \\
\hline \multicolumn{8}{|l|}{ Clorophyta } \\
\hline Tetraselmis chuii & $97,5 \pm 9,9^{b}$ & $0,41 \pm 0,00^{\mathrm{d}}$ & $10,7 \pm 0,5^{\mathrm{cd}}$ & $67,0 \pm 1,1^{\mathrm{a}}$ & $3,7 \pm 0,3^{\mathrm{f}}$ & $14,65 \pm 0,1^{\mathrm{e}}$ & $0,68 \pm 0,001^{\mathrm{c}}$ \\
\hline
\end{tabular}

$\mu$ : duplicación de células por día; letras diferentes denotan diferencias significativas
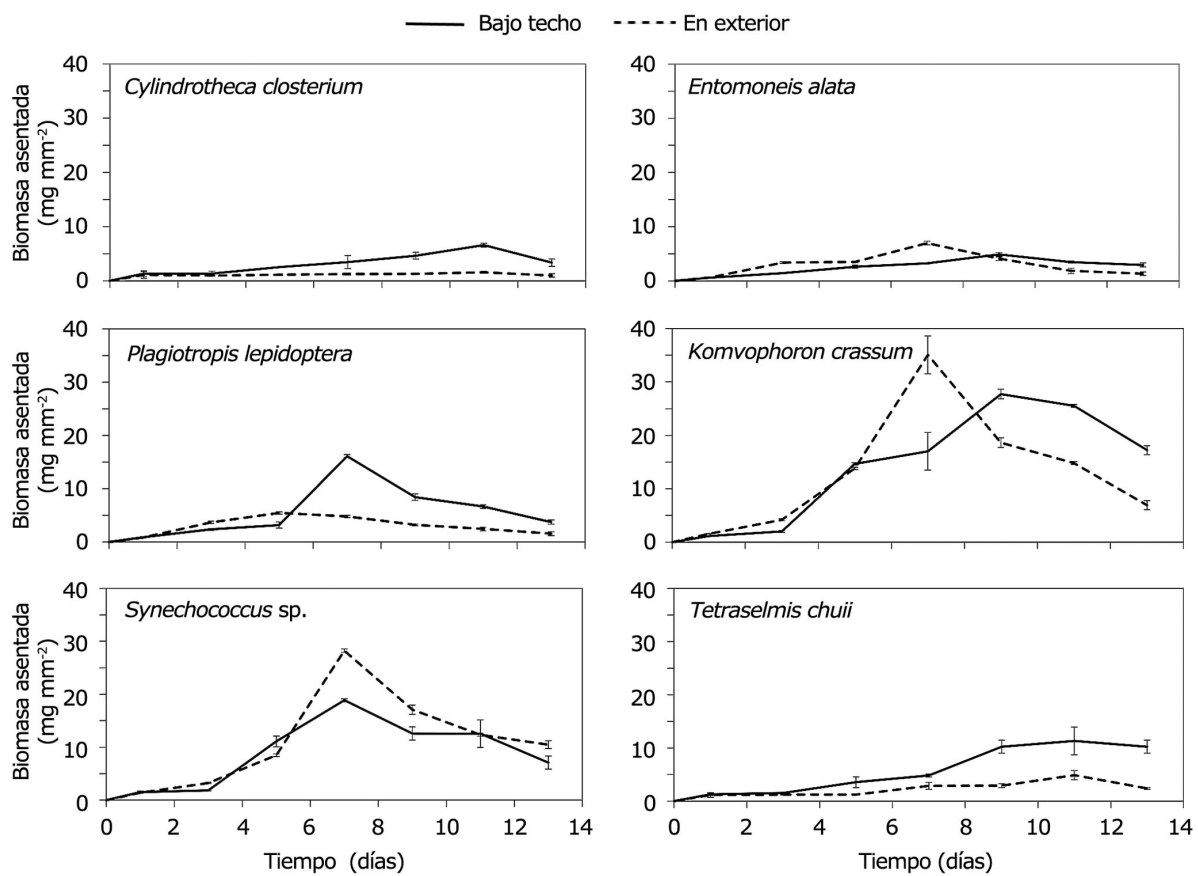

Figura 3. Producción de biomasa $\left(\mathrm{mg} \mathrm{mm}^{-2}\right)$ de 6 especies de microalgas bentónicas del Caribe cultivadas en sistema bentónico sobre placas de PVC inmersas en acuarios de $10 \mathrm{~L}$ con F/2, bajo techo y en exterior. Las barras verticales corresponden al error estándar / Biomass production ( $\mathrm{mg} \mathrm{mm}^{-2}$ ) of 6 species of benthic microalgae from the Caribbean grown in benthic system on PVC plates immersed in aquariums of $10 \mathrm{~L}$ with $\mathrm{F} / 2$, under indoor and outdoor conditions. The vertical bars correspond to the standard error

\section{COMPOSICIÓN PROXIMAL}

El contenido de proteínas osciló entre 9 y 37\% del peso seco (Tabla 2), siendo mayor en C. closterium, seguido de los de E. alata y P. lepidoptera y menores en K. crassum y Tetraselmis chuii $(\mathrm{gl}=5, \mathrm{~F}=344,354, P<0,001)$. El porcentaje de carbohidratos osciló entre 2 y $67 \%$ en peso seco (Tabla 2), presentando los mayores valores en T. chuii, siguiéndole las cianobacterias, y los valores más bajos los presentó $C$. closterium ( $\mathrm{gl}=5, \mathrm{~F}=664,358, P<0,001)$. El contenido de lípidos estuvo entre 4 y $50 \%$ del peso seco total (Tabla 2), mostrando los mayores valores E. alata, seguida de P. lepidoptera y Synechococcus sp. mientras que el valor más bajo lo presentó $T$. chuii $(\mathrm{gl}=5, \mathrm{~F}=1626,929$, $P<0,001)$. En cuanto al contenido de energía, ésta varió entre 14,65 y 23,48 $\mathrm{J} \mathrm{mg}^{-1}$ (Tabla 2) presentándose mayores valores en $E$. alata seguida de $P$. lepidoptera, y los más bajos en $T$. chuii $(\mathrm{gl}=5, \mathrm{~F}=220,97, P<0,001)$. La relación proteínas / energía estuvo entre 0,43 y 1,94 (Tabla 2), siendo mayores los valores en $C$. closterium y los más bajos en $K$. crassum y Synechococcus $\mathrm{sp} .(\mathrm{gl}=5, \mathrm{~F}=282,40, P<0,0001)$. 
Se encontró una correlación significativa entre los valores de densidad máxima en cultivo planctónico y el contenido de lípidos $(\mathrm{n}=6, \mathrm{r}=0,559, P=0,016)$. No se encontró ninguna correlación significativa entre los valores densidad máxima y $\mu$ de las microalgas con el contenido de proteínas $(\mathrm{n}=6, \mathrm{r}=-0,199, P=0,427)$, carbohidratos $(\mathrm{n}=6, \mathrm{r}=0,342$, $P=0,165)$, energía $(\mathrm{n}=6, \mathrm{r}=0,358, P=0,145)$ ni relación proteínas / energía $(\mathrm{n}=6, \mathrm{r}=-0,386, P=0,114)$ de las dietas.

\section{EXPERIMENTO DE CULTIVO EN SISTEMA BENTÓNICO}

Las placas de PVC desprovistas de microalgas alcanzaron valores máximos de biomasa algal seca adherida entre 1,1 y $35 \mathrm{mg} \mathrm{mm}^{-2}$ luego de 5 a 11 días de cultivo (Fig. 3). Las mayores biomasas sobre placas la presentaron $K$. crassum y le siguió Synechococcus sp. mientras que las menores se registraron en C. closterium y E. alata. Las microalgas $K$. crasum, $T$. chuii. P. lepidoptera y $C$. closterium mostraron mayor producción de biomasa en condiciones dentro del laboratorio $(P<0,05)$ mientras que en Synechococcus sp. se verificó mayor producción de biomasa cuando se cultivó en exterior $(P<0,05)$ y en $E$. alata no se encontraron diferencias en los dos ambientes $(P>0,05)$. Los valores de $\mu$ oscilaron entre 0,12 y 0,74 (Tabla 3 ), mayores valores se obtuvieron con las microalgas K. crassum, Synechococcus sp. y P. lepidoptera, mientras que los menores se presentaron en las microalgas $C$. closterium y $T$. chuii $(\mathrm{gl}=5, \mathrm{~F}=92,60$, $P<0,001)$. Para la mayoría de microalgas no se encontraron diferencias significativas en el crecimiento en condiciones bajo techo y en exterior, solo en E. alata, mayores valores se registraron en las mantenidas en exterior $(\mathrm{g} \mathrm{l}=5, \mathrm{~F}=$ $5,21, P=0,0316)$.

\section{Discusión}

El presente estudio puede considerarse entre los primeros esfuerzos reportados sobre el aislamiento y evaluación del potencial de microalgas bentónicas del Caribe para ser usadas como alimento en maricultura. Se proveen las características morfológicas, composición proximal y crecimiento de 6 cepas pertenecientes a 3 divisiones algales, las cuales demuestran su potencial nutritivo y productivo para ser usadas como alimento en acuicultura. Con esta información y la disponibilidad de las mismas en la Colección de Microalgas UMC-MA 205 de la Universidad del Magdalena, puede contribuir a su utilización en el desarrollo de la acuicultura especialmente de la región Caribe, así como de otras zonas o especies tropicales.

Los diversos tamaños de las microalgas aisladas permiten utilizarlas como alimento en diferentes fases del desarrollo de organismos acuáticos de interés comercial y/o para el zooplancton usado en su alimentación. Los pequeños tamaños de las cianofitas aisladas $(<2,5 \mu \mathrm{m})$ serían consideradas de gran potencial para alimentar larvas de bivalvos (Raby et al. 1997) u organismos zooplanctónicos usados como alimento vivo (Motwani \& Gorokhova 2013), cuyas pequeñas bocas y carencia de estructuras externas de trituración les impide ingerir partículas de mayor tamaño. Adicionalmente, su capacidad para producir sustancias extracelulares poliméricas que facilitan su adhesión al sustrato (Scott et al. 1996), puede actuar como fuente de alimento durante las fases de asentamiento y post-larvas (Kawamura et al. 1995). Por otro lado, el tamaño intermedio de la clorófita $T$. chuii $(10 \mu \mathrm{m})$ resulta apropiado para ser usado en larvas de gasterópodos (Aldana-Aranda et

\begin{tabular}{|c|c|c|c|c|}
\hline Microalgas & $\begin{array}{l}\text { Biomasa máxima } \\
\text { bajo techo }\left(\mathrm{mg} \mathrm{cm}^{-2}\right)\end{array}$ & $\begin{array}{l}\text { Biomasa máxima en } \\
\text { exterior }\left(\mathrm{mg} \mathrm{cm}^{-2}\right)\end{array}$ & $\begin{array}{l}\mu \text { bajo techo } \\
\left(\operatorname{div} \operatorname{dia}^{-1}\right)\end{array}$ & $\begin{array}{l}\mu \text { en exterior } \\
\left(\operatorname{div} \operatorname{dia}^{-1}\right)\end{array}$ \\
\hline \multicolumn{5}{|l|}{ Bacillariophyta } \\
\hline Cylindrotheca closterium & $6,57 \pm 0,34^{\mathrm{d}}$ & $1,28 \pm 0,06^{\mathrm{d}}$ & $0,24 \pm 0,04^{\mathrm{cb}}$ & $0,12 \pm 0,04^{\mathrm{c}}$ \\
\hline Entomoneis alata & $4,88 \pm 0,34^{\mathrm{e}}$ & $4,65 \pm 0,34^{\mathrm{c}}$ & $0,37 \pm 0,01^{\mathrm{b}}$ & $0,56 \pm 0,00^{\mathrm{a}}$ \\
\hline Plagiotropis lepidoptera & $6,12 \pm 0,29^{\mathrm{d}}$ & $5,45 \pm 0,19^{\mathrm{c}}$ & $0,69 \pm 0,00^{\mathrm{a}}$ & $0,67 \pm 0,01^{\mathrm{a}}$ \\
\hline \multicolumn{5}{|l|}{ Cyanophyta } \\
\hline Komvophoron crassum & $27,73 \pm 1,57^{\mathrm{a}}$ & $35,06 \pm 3,52^{\mathrm{a}}$ & $0,57 \pm 0,00^{\mathrm{a}}$ & $0,74 \pm 0,02^{\mathrm{a}}$ \\
\hline Synechococcus sp. & $18,87 \pm 0,29^{\mathrm{b}}$ & $28,24 \pm 0,32^{\mathrm{b}}$ & $0,61 \pm 0,02^{\mathrm{a}}$ & $0,72 \pm 0,01^{\mathrm{a}}$ \\
\hline \multicolumn{5}{|l|}{ Clorophyta } \\
\hline Tetraselmis chuii & $11,32 \pm 1,23^{\mathrm{c}}$ & $2,88 \pm 0,34^{\mathrm{d}}$ & $0,31 \pm 0,01^{\mathrm{b}}$ & $0,23 \pm 0,06^{\mathrm{bc}}$ \\
\hline
\end{tabular}

$\mu$ : duplicación de células por día; letras diferentes denotan diferencias significativas 
al. 1991), camarones (Ronquillo et al. 1997, Okauchi \& Tokuda 2003, Pérez-Morales et al. 2016) y peces (Reitan et al. 1997). Mientras que los grandes tamaños de las diatomeas aisladas $(>30 \mu \mathrm{m})$, las hace útiles para postlarvas y juveniles de gasterópodos (Kawamura et al. 1995, Capinpin 2015), equinodermos (Shi et al. 2013) y crustáceos (Martins et al. 2014).

La forma de crecimiento de alta adhesión al sustrato de E. alata, P. lepidoptera y T. chuii, sugiere que estas microalgas pueden ser altamente digeribles para postlarvas de gasterópodos, ya que se ha reportado que las microalgas con este tipo de crecimiento son fácilmente fragmentadas por parte de la rádula y su contenido puede ser absorbido (Kawamura et al. 1995, Onitsuka et al. 2007). Resultados positivos en el desarrollo gonadal, crecimiento y/o supervivencia han sido hallados en postlarvas de gasterópodos usando como alimento especies de diatomeas del mismo género (Carbajal-Miranda et al. 2005, Viana et al. 2007, Koike et al. 2011), pero aparentemente Tetraselmis suministrada en monocultivo no proporciona estos resultados (Leighton 2008).

Los altos valores de densidad celular en sistema de cultivo planctónico presentados por la cianobacteria Synechococcus sp. y la clorófita T. chuii $\left(>96 \times 10^{5}\right.$ cél $\left.\mathrm{mL}^{-1}\right)$ sugieren que estas especies son ideales en cultivos planctónicos o inóculos con alta densidad algal sin importar que esto se logre en un periodo de tiempo relativamente largo (8 a 10 días). Mientras que los altos valores de crecimiento $\mu$ en sistema planctónico obtenidos con las microalgas $E$. alata y $K$. crassum $\left(>0,7\right.$ div día $\left.^{-1}\right)$ indican que estas microalgas son apropiadas para producir algas en menor densidad o inóculos en un corto periodo de tiempo ( $<$ 4 días). Los valores de densidad y/o crecimiento logrados en este estudio son menores a los reportados en especies similares como Synechococcus elongatus (24,3 x $10^{6}$ cél $\mathrm{mL}^{-1}$, Sánchez-Saavedra et al. 2010), Entomoneis puntuclata (1,73 div día ${ }^{-1}$, Knuckey et al. 2002) y Komvophoron sp. (2,98 div día ${ }^{-1}$, Jiménez-Valera \& Sánchez-Saavedra 2016), pero mayores a los reportados para el género Tetraselmis (1-3 x $10^{5}$ cél $\mathrm{mL}^{-1}$ y 0,11-0,56 div día ${ }^{-1}$, Brown et al. 1998, Jiménez-Valera \& Sánchez-Saavedra 2016). Se ha sugerido que las microalgas de menor tamaño presentan mayores valores de crecimiento que aquellas más grandes debido a que tienen una mayor relación superficie/volumen y una estructura menos compleja, lo que hace que absorban nutrientes a una mayor velocidad e inviertan menos recursos en producir organelos (Reynolds 2006). En el presente estudio, la falta de correlaciones entre el crecimiento de las microalgas estudiadas con su tamaño, área, peso y relación área/peso no soportan esta hipótesis, al igual que no lo hacen otros estudios con diatomeas (Correa-Reyes et al. 2001, Knuckey et al. 2002).
Altos contenidos de proteínas y relación proteína/energía fueron hallados para las diatomeas $C$. closterium, E. alata y P. lepidoptera (26\% y $\left.1,16 \mathrm{mg} \mathrm{J}^{-1}\right)$ siendo valores mayores o iguales a lo reportado previamente para especies tales como Cylindrotheca fusisformis $\left(20 \%\right.$ y $0,72 \mathrm{mg} \mathrm{J}^{-1}$, Shi et al. 2013), Cylindrotheca sp. (8\% y $0,83 \mathrm{mg} \mathrm{J}^{-1}$, Chen 2007), E. punctulata (16\% y $0,99 \mathrm{mg} \mathrm{J}^{-1}$, Knuckey et al. 2002), P. lepidoptera (11-33\% 0,86-2,50 mg J'-1, CorreaReyes et al. 2001, Sánchez-Saavedra 2006) y Chaetoceros muelleri (0,58 $\mathrm{mg} \mathrm{J}^{-1}$, Saucedo et al. 2003). Altos valores de crecimiento y/o supervivencia se han registrado en moluscos alimentados con géneros de diatomeas obtenidas en este estudio (Knuckey et al. 2002, Uriarte et al. 2006, Chen 2007, Viana et al. 2007). Entre mayor es el contenido de proteínas de las microalgas usadas como alimento, mayores son los valores de supervivencia y/o crecimiento de postlarvas y juveniles de bivalvos (Utting 1986), gasterópodos (Bautista-Teruel \& Millamena 1999, Carbajal-Miranda et al. 2005), equinodermos (Heflin et al. 2012), así como de crustáceos (Huo et al. 2014) y peces (Arce-Uribe \& Luna-Figueroa 2003) alimentados con zooplancton enriquecido con microalgas de alto contenido proteico. Las proteínas del alimento son principalmente usadas para el crecimiento, sin embargo, cuando en la dieta no se suministran suficientes fuentes energéticas, los animales usan las proteínas como fuente de energía (Cowey \& Sargent 1972, Bautista-Teruel \& Millamena 1999). De allí que la alta relación proteína/energía se considere importante para maximizar el crecimiento (Saucedo et al. 2013, Huo et al. 2014). Teniendo en cuenta los altos contenidos de proteínas y relación proteínas/energía de las diatomeas aisladas en este estudio, puede considerarse que estas tienen un alto potencial nutritivo para organismos acuáticos de alimentación bentónica.

Los altos contenidos de lípidos de las diatomeas E. alata y P. lepidoptera ( $>45 \%$ de peso seco) son mayores a los reportados previamente en especies como E. punctulata (29\%, Knuckey et al. 2002), y P. lepidoptera (8-12\%, Sánchez-Saavedra 2006, Correa-Reyes et al. 2009). Aunque los lípidos son muy importantes porque proveen energía, fosfolípidos, ácidos grasos poliinsaturados y vitaminas (Fleming et al. 1996), su exceso en la dieta puede afectar negativamente la ingesta, crecimiento y supervivencia, así como aumentar la adiposidad en los tejidos (Zhao et al. 2015). Luego, estas diatomeas pueden ser especialmente útiles si son suministradas mezcladas con otras microalgas de bajo contenido de lípidos o bien antes de alcanzar etapas del desarrollo con altas demandas energéticas como las de desove o asentamiento. Durante estas etapas, los lípidos acumulados en los tejidos de larvas y post-larvas tempranas pueden usarse como reservas energéticas, permitiéndoles superar las limitaciones alimentarias exógenas que experimentan (Gallager et al. 1986, Carboni et al. 2012). 
Los altos contenidos de carbohidratos registrados para $T$. chuii, K. crassum y Synechococcus sp. (> 50\%) son mayores que los reportados para los géneros Tetraselmis (8-26\%, Brown et al. 1998, Renaud et al. 1999, Matias-Peralta et al. 2012), Komvophoron (4-12\%, Jiménez-Valera 2016) y Synechococcus (15\%, Becker 1994). Altos contenidos de carbohidratos en la dieta (35-60\%) se han asociado a mayor crecimiento larvario y de juveniles tempranos en moluscos (Brown et al. 1998) y en equinodermos (Xia et al. 2015). Los carbohidratos son importantes en la dieta de organismos acuáticos debido a que son una fuente inmediata de energía (Mann \& Gallager 1985), sin embargo, su exceso puede inhibir la ingesta (Fleming et al. 1996). Cianobacterias de los géneros hallados en este estudio han sido usadas eficientemente como alimento por organismos zooplanctónicos como Artemia (Jiménez-Valera \& SánchezSaavedra 2016), copépodos (Motwani \& Gorokhova 2013) y rotíferos (Hirayama et al. 1979), así como por juveniles de camarón (Kent et al. 2011) y larvas de bivalvos (Gallager et al. 1994). Es así como la clorófita y cianobacterias aisladas pueden resultar muy útiles para ser mezcladas con otras, especialmente en fases del desarrollo donde hay demandas altas de energía como en las fases post-larval y juvenil.

Los altos valores de producción de biomasa adherida a sustratos $\left(>28 \mathrm{mg} \mathrm{cm}^{-2}\right)$ presentado por las cianobacterias $K$. crassum y Synechococcus sp. sugieren que estas microalgas son ideales para alimentar organismos que tienen altos requerimientos de biomasa algal tales como 'spats' y juveniles de abalones (Parker et al. 2007, Araya et al. 2010). Mientras que los mayores valores de crecimiento en sistema bentónico presentados por K. crassum, Synechococcus sp. y P. lepidoptera $\left(>0,6\right.$ div día $\left.{ }^{-1}\right)$ resultan ideales para producir una biomasa algal moderada en el menor tiempo posible, lo cual es requerido en el asentamiento y las postlarvas tempranas de abalones que no toleran exceso de biomasa algal (Leighton 2008). Los valores de biomasa y/o crecimiento hallados en este estudio son mayores a los reportados previamente en cianobacterias como Microcoleus vaginatus (1,1 $\mathrm{mg} \mathrm{cm}^{-2}$, Lan et al. 2017), Nannochloropsis oculata (1,6 mg cm$~^{-2}$, Shen et al. 2014), Scenedesmus obliquus y Nitzschia palea $\left(0,3 \mathrm{mg} \mathrm{cm}^{-2}\right.$, Schnurr et al. 2013).

La mayor producción de biomasa adherida a sustratos obtenida en el sistema de cultivo bentónico bajo condiciones bajo techo en comparación con los cultivos en exterior en la mayoría de las microalgas estudiadas, coincide con lo encontrado en otras microalgas cultivadas en el trópico como Chaetoceros calcitrans, Chaetoceros muelleri (Velasco et al. 2016) y Amphora sp. (De la Peña 2007), así como en el invierno y/o primavera para C. muelleri (López-Elías et al. 2005) y Nannochloropsis sp. (Pérsico et al. 2011). Los cultivos algales en condiciones exterior estuvieron expuestos a mayores valores de intensidad lumínica, los cuales pueden causar fotoinhibición (Wahidin et al. 2013) y a muy altas temperaturas, las cuales pueden provocar el descenso del crecimiento (Sandnes et al. 2005). Adicionalmente, en condiciones exterior existe una mayor probabilidad de que los cultivos se contaminen con zooplancton, otras microalgas, bacterias y/o virus, lo cual afecta negativamente su crecimiento debido a su consumo, producción de agentes alguicidas, reducción de la disponibilidad de nutrientes por competencia y/o cambios estructurales de las células algales (Grossart 1999, Wang et al. 2013, Lan et al. 2015).

La mayor o igual producción de biomasa adherida de las cianobacterias Synechococcus sp. y E. alata cultivadas en exterior en comparación a aquellas mantenidas bajo techo, sugiere que estas microalgas son tolerantes a los cambios ambientales y pueden aprovechar las condiciones de alta temperatura e iluminación para producir más biomasa, como se ha registrado previamente en otras cianobacterias como Microcoleus vaginatus (Lan et al. 2015).

En conclusión, todas las microalgas bentónicas aisladas parecen tener un potencial para ser producidas y usadas como alimento en acuicultura ya que aportan diferentes nutrientes y características que las hacen útiles para este fin. Las diatomeas E. alata, P. lepidoptera y C. closterium tienen tamaños grandes, además de que aportan altos contenidos de proteínas y optima relación proteína/energía. E. alata adicionalmente presenta altos valores de crecimiento en sistema planctónico y bentónico, y aporta altos contenido de lípidos y energía, por lo que podrían servir para alimentar bivalvos, gasterópodos, equinodermos, crustáceos y organismos zooplanctónicos usados como alimento vivo de peces. Las cianobacterias K. crassum y Synechococcus sp. presentaron características ideales para ser usadas como alimento de gasterópodos, zooplancton y larvas de bivalvos, tales como pequeños tamaños celulares, alto contenido de carbohidratos, además de los altos valores de crecimiento y biomasa adherida al sustrato, especialmente cuando son cultivadas en exterior. Mientras que la clorófita $T$. chuii tiene una alta capacidad de producción algal en cultivo planctónico, un tamaño intermedio y puede aportar un alto contenido de carbohidratos, siendo apropiada para alimentar bivalvos y equinodermos. El paso a seguir es validar los resultados obtenidos a una mayor escala de producción, así como probar su uso en especies tropicales de interés en acuicultura.

\section{Agradecimientos}

Los autores agradecen el apoyo de Luis Alfonso Vidal y Santiago Fraga Rivas para la identificación de las microalgas, Pedro Toledo y Eduardo Uribe de la Universidad Austral de Chile por su apoyo en los análisis proximales y adiestramiento en las técnicas de cultivo, así como al personal del Laboratorio de Moluscos y Microalgas de la Universidad del Magdalena quienes apoyaron las labores de aislamiento y cultivo. Este trabajo fue financiado por los proyectos 013-2011 y 022-2016 del fondo FONCIENCIAS de la Universidad del Magdalena. 


\section{LiTERATURA CITADA}

Aldana-Aranda D, A Lucas, T Bruit, M Andrade, E Garcia, N Maginot \& M Le Pennec. 1991. I. Observations on ingestion and digestion of unicellular algae by Strombus gigas larvae (Mollusca, Gastropoda) using epifluorescence microscopy. Aquaculture 92: 359-366.

Almaguer Y, E Alfonso \& S Leal. 2004. Aislamiento y cultivo de dos especies de diatomeas bentónicas. Revista de Investigaciones Marinas 25(1): 57-64.

Alvarez-Lajonchère L \& L Ibarra-Castro. 2013. Aquaculture species selection method applied to marine fish in the Caribbean. Aquaculture 408/409: 20-29.

AOAC. 2000. Official methods of analysis of AOAC International, $2200 \mathrm{pp}$. Association of Analytical Communities, Gaithesburg.

Araya $R$, C Bahamondes, K Barahona \& F SilvaAciares. 2010. Utilización de una biopelícula microalgal multiespecífica para optimizar la fijación larval y el crecimiento de abalón (Haliotis rufescens) en un criadero comercial. Revista de Biología Marina y Oceanografía 45(1): 59-69.

Arce-Uribe E \& J Luna-Figueroa. 2003. Efecto de dietas con diferente contenido proteico en las tasas de crecimiento de crías del Bagre del Balsa Ictalurus balsanus (Pisces: Ictaluridae) en condiciones de cautiverio. Aquatic 18: 39-47.

Barreto-Hernández A \& LA Velasco. 2014. Aislamiento y cultivo de microalgas bentónicas del caribe colombiano bajo diferentes condiciones de temperatura. Intropica 9: 23-32.

Barsanti L \& P Gualtieri. 2005. Algae anatomy, biochemistry and biotechnology, 301 pp. Taylor \& Francis Group, Boca Raton.

Bautista-Teruel MN \& OM Millamena. 1999. Diet development and evaluation for juvenile abalone, Haliotis asinina: protein/energy levels. Aquaculture 178: 117-126.

Becker EW. 1994. Microalgae: Biotechnology and microbiology, 280 pp. Cambridge University Press, New York.

Bligh EG \& WJ Dyer. 1959. A rapid method of total lipid extraction and purification. Canadian Journal of Biochemistry and Physiology 37(8): 911-917.

Brokordt KB \& HE Guderley. 2004. Energetic requirements during gonad maturation and spawning in scallops: sex differences in Chlamys islandica (Müller, 1776). Journal of Shellfish Research 23: 25-32.

Brown M, S Jeffrey, J Volkman \& G Dunstan. 1997. Nutritional properties of microalgae for mariculture. Aquaculture 151: 315-331.

Brown M, M McCausland \& K Kowalski. 1998. The nutritional value of four Australian microalgal strains fed to Pacific oyster Crassostrea gigas spat. Aquaculture 165: 281-293.

Capinpin E. 2015. Settlement of the tropical abalone Haliotis asinine on different diatoms. International Journal Fauna and Biological Studies 2(1): 30-34.

Carbajal-Miranda MJ, MDP Sánchez-Saavedra \& JA Simental. 2005. Effect of monospecific and mixed benthic diatom cultures on the growth of red abalone postlarvae Haliotis rufescens. Journal of Shellfish Research 24(2): 401-405.
Carboni S, J Vignier, M Chiantore, D Tocher \& H Migaud. 2012. Effects of dietary microalgae on growth, survival and fatty acid composition of sea urchin Paracentrotus lividus throughout larval development. Aquaculture 324/325: 250-258.

Chen YC. 2007. Immobilization of twelve benthic diatom species for long-term storage and as feed for post-larval abalone Haliotis diversicolor. Aquaculture 263: 97-106.

Cognie B, L Barille \& Y Rince. 2001. Selective feeding of the oyster Crassostrea gigas fed on a natural microphytobenthos assemblage. Estuaries 24: 126-131.

Correa-Reyes JG, MD Sánchez-Saavedra, DA SiqueirosBeltrones \& N Flores-Acevedo. 2001. Isolation and growth of eight strains of diatoms, cultures under two light conditions. Journal of Shellfish Research 20(2): 603-610.

Correa-Reyes JG, MP Sánchez-Saavedra, MT Viana, N Flores-Acevedo \& C Vásquez-Peláez. 2009. Effect of eight benthic diatoms as feed on the growth of red abalone (Haliotis rufescens) postlarvae. Journal of Applied Phycology 21: 387-393.

Cowey CB \& JR Sargent. 1972. Fish nutrition. Advances in Marine Biology 10: 383-492.

Curbelo R, S Leal, N Núñez, P Quintana, I Benguela, D Muñóz \& Y Almaguer. 2004. Cultivo de la microalga bentónica Navicula sp. para la alimentación de las primeras postlarvas de camarón blanco. Revista de Investigaciones Marinas 25(2): 143-150.

De la Peña MR. 2007. Cell growth and nutritive value of the tropical benthic diatom, Amphora sp. at varying levels of nutrients and light intensity, and different culture locations. Journal of Applied Phycology 19: 647-655.

Fleming AE, RJ Van-Barneveld \& PW Hone. 1996. The development of artificial diets for abalone: A review and future directions. Aquaculture 140: 5-53.

Gallager SM, R Mann \& GC Sasaki. 1986. Lipid as an Index of growth and viability in three species of bivalve larvae. Aquaculture 56: 81-103.

Gallager SM, JB Waterbury \& DK Stoecker. 1994. Efficient grazing and utilization of the marine cyanobacterium Synechococcus sp. by larvae of the bivalve Mercenaria mercenaria. Marine Biology 119: 251-259.

Grossart HP. 1999. Interactions between marine bacteria and axenic diatoms (Cylindrotheca fusiformis, Nitzschia laevis, and Thalassiosira weissflogii) incubated under various conditions in the lab. Aquatic Microbial Ecology 19: 1-11.

Guillard RRI. 1973. Methods for microflagellates and nannoplankton. In: Stein JR (ed). Handbook of phycological methods. Culture methods and growth measurements, pp. 69-85. Cambridge University Press, New York.

Guillard RRL \& JH Ryther. 1962. Studies of marine planktonic diatoms. I Cyclotella nana Hustedt and Detonula confervacea (Cleve) Gran. Canadian Journal of Microbiology 18: 229-239.

Heflin LE, VK Gibss, ML Powell, R Makowsky, JM Lawrence, A Lawrence \& SA Watts. 2012. Effect of dietary protein and carbohydrate levels on weight gain and gonad production in the sea urchin Lytechinus variegatus. Aquaculture 358: 253-261 
Hirayama K, K Takagi \& H Kimura. 1979. Nutritional effect of eight species of marine phytoplankton on population growth of the rotifer, Brachiones plicatilis. Bulletin of Japanese Society of Fisheries Science 45(1): 11-16.

Hoek C, DG Mann \& HM Jahns. 1995. Algae: an introduction to phycology, 348 pp. Cambridge University Press, New York.

Hoshaw RW \& JR Rosowski. 1973. Methods for microscopic algae. In: Stein JR (ed). Handbook of phycological methods, Culture methods and growth measurements, pp. 53-67. Cambridge University Press, New York.

Huo YW, M Jun, PP Zhou, M Li, KS Mai \& QC Zhou. 2014. Effects of dietary protein and lipid levels on growth, feed utilization and body composition of juvenile swimming crab, Portunus trituberculatus. Aquaculture 434: 151-158.

Jiménez-Valera S. 2016. Aislamiento y caracterización bioquímica de microalgas de Baja California como alternativas para la producción de lípidos. Tesis de Doctorado, Centro de Investigación Científica y de Educación Superior de Ensenada, Baja California, 191 pp.

Jiménez-Valera S \& MP Sánchez-Saavedra. 2016. Growth and fatty acid profiles of microalgae species isolated from the Baja California Peninsula, Mexico. Latin American Journal of Aquatic Research 44(4): 689-702.

Kawamura T \& R Hirano. 1992. Seasonal changes in benthic diatom communities colonizing glass slides in Aburatsubo bay Japan. Diatom Research 7(2): 227-239.

Kawamura T, T Saidob, H Takami \& Y Yamashita. 1995. Dietary value of benthic diatoms for the growth of post-larval abalone Haliotis discus hannai. Journal of Experimental Marine Biology and Ecology 194: 189-199.

Kawamura T, R Roberts \& C Nicholson. 1998. Factors affecting the food value of diatom strains for post-larval abalone Haliotis iris. Aquaculture 160: 81-88.

Kent M, CL Browdy \& JW Leffler. 2011. Consumption and digestion of suspended microbes by juvenile Pacific white shrimp Litopenaeus vannamei. Aquaculture 319: 363-368.

Keun-Ko S \& S Bum-Hur. 2011. Effects of microalgal species on the settlement and survival of Haliotis discus hannai larvae. Fisheries and Aquatic Sciences 14(4): 339-345.

Knuckey RM, MR Brown, SM Barrett \& GM Hallegraeff. 2002. Isolation of new nanoplanktonic diatom strains and their evaluation as diets for juvenile Pacific oysters (Crassostrea gigas). Aquaculture 211(1): 253-274.

Koike Y, AE Stott, F Ahmed, T Takeuchi, C Strussman, M Yokota, S Segawa \& S Watanabe. 2011. Trials on new methods for seed culture in Japanese abalones. In: Ceccaldi HJ, I Dekeyser, M Girault \& G Stora (eds). Global change: Mankind-marine environment interactions, 13 Proceedings of the 13th French-Japanese Oceanography Symposium. <doi: 10.1007/978-90-481-8630-3_2>

Kwon HK, SJ Oh \& HS Yang. 2013. Growth and uptake kinetics of nitrate and phosphate by benthic microalgae for phytoremediation of eutrophic coastal sediments. Bioresource Technology 129: 387-395.

Lan S, L Wu, D Zhang \& C Hu. 2015. Effects of light and temperature on open cultivation of desert cyanobacterium Microcoleus vaginatus. Bioresource Technology 182: 144150.
Lan S, L Wu, H Yang, D Zhang \& C Hu. 2017. A new biofilm based microalgal cultivation approach on shifting sand surface for desert cyanobacterium Microcoleus vaginatus. Bioresource Technology 238: 602-608.

Leal S, MA Medina, MA Guerrero, P Piña, M Nieves \& R Curbelo. 2013. Concentración y composiciones orgánica y proximal de dos especies de diatomeas bentónicas a diferentes salinidades. Ecosistemas y Recursos Agropecuarios 29(1): 45-52.

Leighton P. 2008. Abalone hatchery manual. Aquaculture Explained 28: 1-88. Aquaculture Technical Section, Aquaculture Development Division, Dublin. $<$ http:// www.bim.ie/media/bim/content/publications/bimno_25 Abalone_Hatchery_Manual_2008.pdf>

López-Elías JA, D Voltolina, F Enríquez-Ocaña \& G Gallegos-Simental. 2005. Bajo techo and exterior mass production of the diatom Chaetoceros muelleri in a Mexican commercial hatchery. Aquacultural Engineering 33(3): 181-191.

Lovatelli A \& S Sarkis 2011. A regional shellfish hatchery for the Wider Caribbean: Assessing its feasibility and sustainability. FAO Regional Technical Workshop, 18-21 October 2010, Kingston, Jamaica. FAO Fisheries and Aquaculture Proceedings 19: 1-246.

Mann R \& SM Gallager. 1985. Growth, morphometry and biochemical composition of the wood boring molluscs Teredo navalis L. Bankia gouldi (Bartsch), and Nototeredo knoxi (Bartsch) (Bivalvia: Teredinidae). Journal of Experimental Marine Biology and Ecology 85: 229-251.

Martins TG, C Odebrecht, LV Jensen, MGM D'Oca \& W Wasielesky. 2014. The contribution of diatoms to blioflocs lipid content and the performance of juvenile Litopenaeus vannamei (Boone, 1931) in a BFT culture system. Aquaculture Research 47(4): 1-12.

Matias-Peralta HM, FM Yusoff, M Shariff \& S Mohamed. 2012. Reproductive performance, growth and development time of a tropical harpacticoid copepod, Nitocra affinis californica Lamg, 1965 fed with different microalgal diets. Aquaculture 344-349: 168-173.

Motwani NH \& E Gorokhova. 2013. Mesozooplankton grazing on Picocyanobacteria in the Baltic Sea as inferred from molecular diet analysis. PLoS ONE 8(11): <https://doi. org/10.1371/journal.pone.0079230>

Najmudeen TM. 2017. Competitive interactions between two marine benthic microalgae in mixed culture. Indian Journal of Geo-Marine Sciences 46(7): 1417-1422.

Okauchi M \& M Tokuda. 2003. Trophic value of the unicellular diatom Phaeodactylum tricornutum for larvae of Kuruma Prawn, Penaeus japonicus. National Research Institute of Aquaculture Fisheries Research Agency. Nansei-cho, Watari-gun, Mie. 516-0193, Japan. <http://citeseerx.ist. psu.edu/viewdoc/download?doi=10.1.1.549.1881\&rep=re p1\&type $=$ pdf $>$

Onitsuka T, T Kawamura, S Ohashi, T Horii \& Y Watanabe. 2007. Dietary value of benthic diatoms for post-larval abalone Haliotis diversicolor associated with feeding transitions. Fisheries Science 73: 295-302. 
Parker F, M Davidson, K Freeman, S Hair \& S Daume 2007. Investigation of optimal temperature and light conditions for three benthic diatoms and their suitability to commercial scale nursery culture of abalone (Haliotis laevigata). Journal of Shellfish Research 26: 751-761.

Pérez-Morales A, CJ Band-Schmidth \& SF Martinez-Diaz. 2016. Changes in mortality rates during the larval stage of the Pacific white shrimp (Litopenaeus vannamei) on the basis of algal (Chaetoceros calcitrans or Tetraselmis suecica) food density. Ecosistemas y Recursos Agropecuarios 3(9): 415-420.

Pérsico MM, M Moris, ED Tranier, AN Zanazzi, AA Saubidet \& M Beligni. 2011. Evaluación de un sistema exterior de cultivo masivo de la microalga marina Nannochloropsis oculata, en una zona templada oceánica de Argentina. Revista Latinoamericana de Biotecnología Ambiental y Algal 2(1): 30-48.

Raby D, M Mingelbier, J Dodson, B Klein, Y Lagadeuc \& L Legendre. 1997. Food-particle size and selection by bivalve larvae in a temperate embayment. Marine Biology 127: 665-672.

Reitan KI, JR Rainuzzo, G Oie \& Y Olsen. 1997. A review of the nutritional effects of algae in marine fish Larvae. Aquaculture 155: 207-221

Renaud SM, LV Thinh \& DL Parry. 1999. The gross chemical composition and fatty acid composition of 18 species of tropical Australian microalgae for possible use in mariculture. Aquaculture 170(2): 147-159.

Reynolds CS. 2006. Ecology of phytoplankton, $550 \mathrm{pp}$. Cambridge University Press, New York.

Rodríguez-Núñez K, P Toledo \& S Arias. 2015. Aislamiento de dos especies de diatomeas con potencial acuícola Bacillariophyceae) en el Pacífico de Costa Rica. Cuadernos de Investigación 8(1): 93-98.

Ronquillo JD, JR Matias, T Saisho \& S Yamasaki. 1997. Culture of Tetraselmis tetrahele and utilization in the hatchery production of different penaeid shrimps in Asia. Hydrobiology 358: 237-244.

Sánchez-Saavedra MD. 2006. The effect of cold storage on cell viability and composition of two benthic diatoms. Aquacultural Engineering 34: 131-136.

Sánchez-Saavedra MD, A Licea-Navarro \& J BernáldezSarabia. 2010. Evaluation of the antibacterial activity of species of phytoplankton. Revista de Biología Marina y Oceanografía 45(3): 531-536.

Sandnes JM, JMT Källqvist, D Wenner \& HR Gislerød. 2005. Combined influence of light and temperature on growth rates of Nannochloropsis oceanica: linking cellular responses to large-scale biomass production. Journal of Applied Phycology 17(6): 515-525.

Saucedo PE, A González-Jiménez, H Acosta-Salmon, JM Mazon-Suasregui \& JA Ronson-Paulin. 2013. Nutritional value of microalgae-based diets for lions-paw scallops (Nodipecten subnodosus) juveniles reared at different temperatures. Aquaculture 392: 113-119.

Schnurr PJ, GS Espie \& DG Allen. 2013. Algae biofilm growth and the potential to stimulate lipid accumulation through nutrient starvation. Bioresource Technology 136: 337-344.
Scott C, RL Fletcher \& G Bremer. 1996. Observations on the mechanisms of attachment of some marine fouling bluegreen algae. Biofouling 10(1-3): 161-173.

Searcy-Bernal R, L Velez-Espino \& C Anguiano-Beltrán. 2001. Effect of biofilm density on grazing and growth rates of Haliotis fulgens postlarvae. Journal of Shellfish Research 20: 587-591.

Shen Y, C Shen, W Chen \& X Xu. 2014. Attached culture of Nannochloropsis oculata lipid production. Bioprocess and Biosystem Engineering 37: 1743-1748.

Shi C, S Dong, F Wang, Q Gao \& X Tian. 2013. Effects of four fresh microalgae in diet on growth and energy budget of juvenile sea cucumber Apostichopus japonicus (Selenka). Aquaculture 416/417: 296-301.

Simental JA \& MP Sánchez-Saavedra. 2003. The effect of agricultural fertilizer on growth rate of benthic diatoms. Aquacultural Engineering 27: 265-272.

Strickland JDH \& TR Parsons. 1972. A practical handbook of seawater analysis. Fisheries Research Board of Canada, Bulletin 172: 1-310

Uriarte I, R Roberts \& A Farías. 2006. The effect of nitrate supplementation on the biochemical composition of benthic diatoms and the growth and survival of post-larval abalone. Aquaculture 261: 423-429.

Utting SA. 1986. Preliminary study on growth of Crassostrea gigas larvae and spat in relation to dietary protein. Aquaculture 56: 123-138.

Velasco LA, S Carrera \& J Barros. 2016. Isolation, culture and evaluation of Chaetoceros muelleri from the Caribbean as food for the native scallops, Argopecten nucleus and Nodipecten nodosus. Latin American Journal of Aquatic Research 44(3): 557-568.

Viana M, TG Correa, JP Lazo, R Frías-Díaz, E DurazoBeltran \& C Vásquez-Peláez. 2007. Digestive physiology and metabolism of green abalone Haliotis fulgens from postlarvae to juvenile, fed three different diatoms. Aquaculture 271: 449-460.

Vidal LA. 2010. Manual del fitoplancton hallado en la Ciénaga Grande de Santa Marta y cuerpos de aguas aledaños, 348 pp. Fundación Universidad de Bogotá Jorge Tadeo Lozano, Santa Marta.

Vivas-Aguas LJ, L Espinosa, J Sánchez, B Cadavid, P Bautista, M Quintero, J Betancourt, JP Parra, LG Parra, I Cuadrado \& K Ibarra. 2015. Diagnóstico y evaluación de la calidad ambiental marina en el Caribe y Pacífico colombiano. Red de vigilancia para la conservación y protección de las aguas marinas y costeras de ColombiaREDCAM, 310 pp. INVEMAR, Santa Marta.

Wahidin S, A Idris \& SR Muhamad-Shaleh. 2013. The influence of light intensity and photoperiod on the growth and lipid content of microalgae Nannochloropsis sp. Bioresource Technology 129: 7-11.

Wang H, W Zhang, L Chen, J Wang \& T Liu. 2013. The contamination and control of biological pollutants in mass cultivation of microalgae. Bioresource Technology 128: 745-750. 
Watson D, S Daume, J Prince, L Beazley \& B Knott. 2004. The influence of light intensity on the density of different diatoms as feed for juvenile greenlip abalone (Haliotis laevigata). Aquaculture 235: 345-359.

Wood AM, RC Everroad \& LM Wingard. 2005. Measuring growth rates in microalgal cultures. In: Andersen RA (ed). Algal culturing techniques, pp. 269-286. Elsevier, New York.

Xia B, QF Gao, J Wang, P Liu, L Zhang \& Z Zhang. 2015. Effects of dietary carbohydrate level on growth, biochemical composition and glucose metabolism of juvenile sea cucumber Apostichopus japonicus (Selenka). Aquaculture 448: $63-70$.

Xing R, C Wang, X Cao \& Y Chang. 2007. The potential value of different species of benthic diatoms as food for newly metamorphosed sea urchin Strongylocentrotus intermedius. Aquaculture 263: 142-149.
Yang M, W Zhao \& X Xie. 2014. Effects of nitrogen, phosphorus, iron and silicon on growth of five species of marine benthic diatoms. Acta Ecologica Sinica 34: 311-319.

Zhao J, X Wen, S Li, D Zhu \& Y Li. 2015. Effects of dietary lipid levels on growth, feed utilization, body composition and antioxidants of juvenile mud crab Scylla paramamosain (Estampador). Aquaculture 435: 200-206.

Zupo V, F Glaviano, D Caramiello \& M Mutalipassi. 2018. Effects of five benthic diatoms on the survival and development of Paracentrotus lividus post-larvae in the laboratory. Aquaculture 495: 13-20.

Recibido el 25 de junio de 2018 y aceptado el 21 de noviembre de 2018

Editor: Claudia Bustos D. 